\title{
EL TRABAJO SOCIAL FAMILIAR
}

\section{ISABEL RAMIREZ DE MINGO}

Titular de Trabajo Social

Universidad Complutense. Madrid

\section{EL TRABAJO SOCIAL CON FAMILIAS}

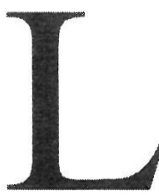

a intervención del trabajador social en el grupo familiar tiene como objetivo la mejora de alguna de las condiciones de sus miembros. Esta mejora implica, sin duda, la movilización de elementos personales y relacionales ${ }^{1}$ : Sentimientos, actitudes, comportamientos, y asimismo movilización y utilización de elementos externos: Recursos materiales, técnicos, servicios.

Además de la movilización de los aspectos anteriormente mencionados, el trabajador social tendrá que recibir y contener diferentes estados emocionales del grupo familiar: Ansiedades, angustias, agresividad, pasividad, y al mismo tiempo tendrá que estimular los aspectos más constructivos y maduros de los mismos. En definitiva, tendrá que movilizar recursos personales y sociales para que la familia, en un plazo más o menos corto, pueda recuperar o adquirir capacidades que les permitan vivir y actuar de una forma más satisfactoria y autónoma.

Así pues, la eficacia de la intervención se podría valorar más con el aumento de la capacidad del grupo familiar para hacerse cargo y superar nuevas dificultades, que con la resolución concreta y específica de la demanda que le ha llevado a acudir al trabajador social.

Para ampliar los aspectos más capacitados, más autónomos, más adultos del grupo familiar, es necesario conocer y comprender de la manera más profunda posible las necesidades básicas que determinan las dificultades y actuación del grupo, los mecanismos que marcan la dinámica social y la interacción que continuamente se establece entre los diferentes elementos.

La intervención del Trabajador social debe ser globalizadora, dirigida a encauzar todos los aspectos que están distorsionados y evitar atender solamente alguno de ellos, parcializándolos. Del mismo modo la intervención irá dirigida no sólo a solucionar el problema del mo-

${ }^{1}$ Klein, M. Love, guilt and reparations, Othesa Work, Llogart Press and Institute of Psychoanalysis, Londres, 1975. 
mento, sino en su conjunto. Así se evitará el satisfacer algún aspecto concreto y distorsionar otros ${ }^{2}$.

El seguimiento de una situación familiar problemática requiere tener un conocimiento de la misma que permita:

- Establecer objetivos que previsiblemente se puedan lograr basados en la movilización de recursos de la propia situación, de recursos sociales y de los que el propio servicio puede ofrecer.

- Determinar de qué manera se llevará a cabo el tratamiento y qué medios y recursos técnicos probablemente se tendrán que emplear.

- Decidir cuáles son los aspectos prioritarios y cuáles los que se han de atender en segundo lugar, dada su menor urgencia, o porque se atenderán paralelamente a los prioritarios, o porque éstos últimos son condición para tratar los primeros.

La atención a la familia empieza cuando el trabajador social establece la primera relación con ésta y con la situación con la que deberá trabajar.

El proceso se inicia en el punto donde se halla la familia, involucrándola en la identificación y localización de sus dificultades y de sus recursos.

\section{NECESIDADES FAMILIARES}

Definir qué es una necesidad social es muy difícil, ya que no todo el mundo participa de los mismos criterios sobre la manera o el modo en que se puede satisfacer, ni en qué medida aquello que siendo absolutamente necesario para un grupo constituye una necesidad menor para otro.

El valor y la significación de las necesidades varía si son definidos desde fuera (por el técnico) o si están definidos desde la propia persona que las vive y las padece ${ }^{3}$.

Las necesidades no son estáticas en los grupos sociales. Por esto es necesario que los profesionales adecúen sus puntos de vista y sus mecanismos de intervención a los diferentes momentos y a los diversos aspectos que una necesidad presenta.

En mi opinión, los problemas que generan las necesidades familiares son multicasuales. A las necesidades propias de las funciones familiares en las distintas etapas del ciclo vital hay que añadir la influencia de factores internos (personales, convivencionales) o externos (sociales, culturales) que pueden ayudar o dificultar el proceso familiar.

2 Rossell, T. La entrevista en el Trabajo Social, Euge, Barcelona, 1989.

${ }^{3}$ Mc Knight, J. Servicios profesionalizados y Asistencia, Blume, Madrid, 1981. 
También las situaciones que generan necesidad tendrán que ver con las actitudes personales, los recursos propios y comunitarios necesarios para hacer frente a la situación; momento de estabilidad e inestabilidad en que afronta la familia la situación; referencia cultural y del grupo de pertenencia en que se mueve la familia: contexto institucional que define y señala las situaciones problemáticas.

Las situaciones familiares que previsiblemente pueden generar necesidad, dificultad o conflicto, vamos a denominarla «situación de riesgo", que la entenderíamos como la situación generada por la interrelación de factores internos y externos. Estos factores sociales de riesgo impiden que en los cambios operados por el normal desarrollo familiar se obtengan nuevas relaciones funcionales o situaciones manejables con los propios recursos de la familia ${ }^{4}$.

Vamos a tratar de exponer ambos factores.

Entre los factores externos apuntamos:

- Carencia de infraestructuras y servicios.

- Falta de servicios para el tiempo libre y de recursos culturales.

- Sociedad en proceso acelerado de transformación.

- Modificación de la escala de valores.

- Desarrollo de la familia nuclear cuando aún ejerce un importante poder de influencia la familia de origen (familia extensa).

- Indices altos de desempleo.

- Inadecuación entre necesidades formativas y recursos disponibles para la formación y la capacitación profesional.

- Deficiencias formativas para el desarrollo de los roles familiares en el contexto del cambio social.

- Falta de recursos asistenciales adecuados para atender las necesidades de la tercera edad, derivadas del progresivo envejecimiento de ciertas poblaciones.

— Falta de comunicación y solidaridad en el tejido social.

Factores internos

- Estructura rígida familiares que entran en contradicción con los calores emergentes.

- Deficiencias formativas para el desarrollo de las capacidades (profesionales, intelectuales, ocupacionales, culturales...).

- Injerencia de las familias de origen en las nucleares.

- Desfase entre los modelos educativos de los padres con respecto a los hijos.

- Matrimonios mayores con menores a su cargo.

${ }^{4}$ Wallace, M. A focal conflict model of marital disorders, Social Casework, FSAA, Nueva York, 1979. 
- Familias con enfermos mentales (mayor riesgo en enfermos mentales adultos dependientes de padres ancianos) o trastornos de la personalidad.

- Familias con toxicómanos y alcohólicos.

- Familias monoparentales.

- Familias prematuras.

- Ocupación de los progenitores. Prostitución y mendicidad, parados o desempleados, horarios de trabajo excesivo o nocturno. Estancias prolongadas en otros lugares distintos a la residencia, por causa laboral.

- Ruptura de relaciones intergeneracionales en la familia nuclear.

- Progenitores procedentes de familias conflictivas.

- Condiciones de sanidad deficientes.

- Progenitor en la cárcel.

- Malas condiciones de habitabilidad: vivienda infradotada ${ }^{5}$.

\section{DEMANDAS FAMILIARES}

La demanda podemos definirla como la petición o solicitud que presenta la familia cuando acude a un servicio y se pone en contacto con el Trabajador social.

En situaciones frecuentes, encontramos que la demanda que se explicita no se corresponde directamente con la necesidad o preocupación principal de la persona que la presenta. Esta no identifica claramente su necesidad o problema y plantea o pide algo que está relacionado con ello ${ }^{6}$.

A través de las familias a las cuales hemos tenido acceso, las demandas que principalmente presentan podríamos catalogarlas en:

- Demandas económicas.

- Demandas de informaciones varias y orientación de recursos. Asimismo, clarificación de dudas respecto a recursos y alternativas sociales.

- Problemas familiares, centrados en la relación entre los miembros de la familia en momentos de reajuste de los roles y las estructuras del grupo familiar después de una muerte, una separación o cambio en su ciclo vital.

- Demandas referidas a problemas de viviendas, tales como pago de atrasos, problemas de infraestructura, inhabitabilidad.

- Demandas de trabajo (aunque se presentan menos de las que 1990.

${ }^{5}$ Ministerio de Asuntos Sociales. Dirección General de Acción Social, Madrid,

${ }^{6}$ Ramírez, L. El Trabajo Social en los servicios de salud mental, EUDEMA, Madrid, 1992. 
se necesitan realmente, sobre todo en los servicios que no tienen programas ni vinculaciones con servicios de contrataciones laborales).

- Demandas referidas a la salud o a las enfermedades.

Hay que tener presente que las demandas que se reciben en un servicio están muy mediatizadas por la oferta de dicho servicio.

Referente al perfil del usuario que mayoritariamente acude a un servicio a presentar demandas, podríamos apuntar que son:

- Mujeres de una edad media (40-45 años).

- Pertenecen a una composición familiar que es prioritariamente familia nuclear, siguiéndole familia extensa y familia monoparental.

- Un alto porcentaje es analfabeto.

- Los ingresos económicos son muy bajos.

- Los índices de paro son muy elevados.

- Baja orientación y preparación para la educación de los hijos.

- Se observa un alto índice de violencia y conflictividad familiar, sobre todo entre las parejas.

\section{PROCESO DE INTERVENCION PROFESIONAL}

Lo esencial a la hora de abordar profesionalmente a la familia no es sólo definir la intervención, sino más bien determinar a partir de qué elementos se efectúa la selección del tipo de intervención, que va unido a la situación real del asistido, las hipótesis de trabajo que se establezcan y los objetivos que pretendemos en la intervención. También influye cómo se ha originado el encuentro entre Trabajador social y la persona asistida, la duración de la intervención y desde dónde se efectúa la misma.

El Trabajador social, en su abordaje a las situaciones familiares, contempla a la familia en su globalidad. En ocasiones dicha intervención se realiza directamente con un solo miembro de la unidad familiar, ante la imposibilidad, por diversos motivos, de hacerlo con todos, pero nunca se pierde la referencia al grupo (unidad convivencial) y la visión de todo él.

\section{TIPOS DE INTERVENCION}

Directas: son las que se dirigen al asistido en una relación frente a frente .

${ }^{7}$ Noriega, C. Model of Social work intervention in crisis resolutions, Tesis Doctorąl. Ohio University, 1971. 
Indirectas: son las que realiza el Trabajador social fuera de la relación personal con el asistido, con el fin de organizar su trabajo, planificar acciones que se realizarán posteriormente y también acciones en beneficio del asistido, pero sin la participación activa de éste.

A continuación vamos a desarrollar detenidamente cada una de estas intervenciones.

\section{Intervención directa}

- Clarificar-apoyar: analizando los distintos aspectos de la situación, para percibirlos de una forma realista. Por otra parte, ver qué factores han influido y contribuido a desencadenar un estado temporal de desorganización en el funcionamiento familiar. También es necesario clarificar la capacidad de cada uno de sus miembros. Las relaciones que tienen entre sí y con personas significativas. La utilización de los recursos ambientales o la posibilidad de acceso a los mismos. Y por último se clarificarán las consecuencias que pueden tener las diferentes alternativas de acción que se escojan.

En esta línea, se trazarán metas de acción específicas y limitadas en el tiempo, que puedan aumentar por una parte la capacidad cognoscitiva de cada uno de los miembros, aminorar sentimientos de angustia y aumentar la esperanza de encontrar soluciones favorables y realistas a los problemas planteados.

- Informar-educar: Tienen como objetivo que se subsanen las eventuales carencias de información correspondientes a los diferentes campos: legislación, derechos, diversos organismos existentes y su utilidad, derecho excepcional a ciertas ayudas, informar en todo lo concerniente al aprendizaje en el campo de la salud, alimentación, cuidado de los niños, organización familiar.

La educación se entiende en el sentido de transmitir un saber y un saber hacer. También como una reeducación, una reinserción social y desarrollo personal.

La acción del Trabajador social está fundamentalmente orientada a modificar la situación de la familia mediante el uso de técnicas dirigidas a:

- Persuadir-influir a través del Consejo: Haciendo recomendaciones con miras a ayudar al asistido a sobreponerse a sus problemas.

Persuasión: Tratando de conseguir que el asistido se una a las propuestas del Trabajador social.

Confrontación: Compulsar al asistido con las consecuencias de sus actos.

- Controlar-ejercer la autoridad: Estableciendo con el asistido un orden en el proceso de ayuda, manejando el tiempo de que se dispone debidamente y consiguiendo que el asistido colabore en la solución de 
sus problemas. En este sentido, el Trabajador social establecerá el tipo de seguimiento que requiera la situación, estableciendo un contrato (horarios, regularidad de los encuentros...), exigiendo que el asistido asuma sus responsabilidades y sus obligaciones.

- Crear nuevas oportunidades: Consiste en ampliar el horizonte relacional de los asistidos, ampliar sus marcos de referencia y permitirles el acceso a nuevas experiencias que los enriquezcan y les produzcan satisfacción. Por ejemplo, ponerles en relación con otras personas y otras instituciones; crearles la oportunidad de abrirse y descubrir otros grupos, experiencias hasta entonces insospechadas; intentar que utilicen estructuras de su medio en las que pudieran participar, utilizando los recursos que estuviesen a su disposición.

- Estructurar una relación de trabajo con el asistido: El objetivo es procurar los medios necesarios para lograr con éxito el cambio que uno se propone, a través de estructurar el tiempo, el espacio y focalizar los objetivos.

\section{Intervención indirecta}

Algunas intervenciones directas dan lugar a una serie de intervenciones indirectas, como son contactos, gestiones entre diversos organismos, redacción de informes y encuestas. Otras se sitúan en el plano del entorno del asistido, ya sea respecto a las personas próximas a él, o bien a nivel colectivo en relación a un conjunto de población (creación de equipamientos, animación de grupos, creación de asociaciones).

Entre los tipos de intervención indirecta, hacemos referencia a los siguientes:

- Organización y documentación: consiste en administrar el tiempo de trabajo, el espacio y los conocimientos que se poseen.

- Planificaciones de intervenciones directas: consiste en organizar acciones previas al comienzo de un proyecto de intervención, especialmente en el trabajo de grupo.

- Intervención en el entorno del asistido: el objetivo es modificar la situación ambiental del asistido, amplicar su inserción social y modificar la actitud que tienen respecto a él personas significativas.

- Colaboración con otros trabajadores sociales: el objetivo es conseguir una mayor atención y seguimiento del asistido.

Por último queremos hacer mención de la derivación, cuando las características de la familia, a través del conocimiento del problema, no pueda ser resuelto por el servicio. Para completar la atención se trasladará al grupo familiar como tal (aunque sólo sea un miembro) a otra institución o servicio especializado más idóneo para su atención. 